\title{
INVESTIGATION OF EROSION RESISTANCE OF GRAY-BROWN SOILS IN THE SOUTHEASTERN SLOPES OF THE GREATER CAUCASUS
}

\author{
Dr.Prof. RANS Aliyev Z.H. \\ Institute of Soil Science and Agrochemistry of the National Academy of Sciences of Azerbaijan
}

\begin{abstract}
In recent years, sharp changes have occurred in the state of sloping lands of Azerbaijan. There was tension from the influence of the anthropogenic factors on the mountain slopes. The fact that the erosion process is reinforced in the research site. Due to lack of agrotechnical measures on the slopes erosion process has been strengthened, soil flooded with soil, physical and chemical properties of the soil have deteriorated, nutritional elements are reduced, vegetation is reduced and destruction limit. For some reason, the purpose of the research was Aqsu, two land cuts were set up to determine the degree of actual erosion in the Qizmeydan village. prevent erosion intensity, take preventive measures to take and implement appropriate measures.
\end{abstract}

Key words: erosion, mountain, meadow, forest, mountain chernozem, silver-black-brown earth and $d$.

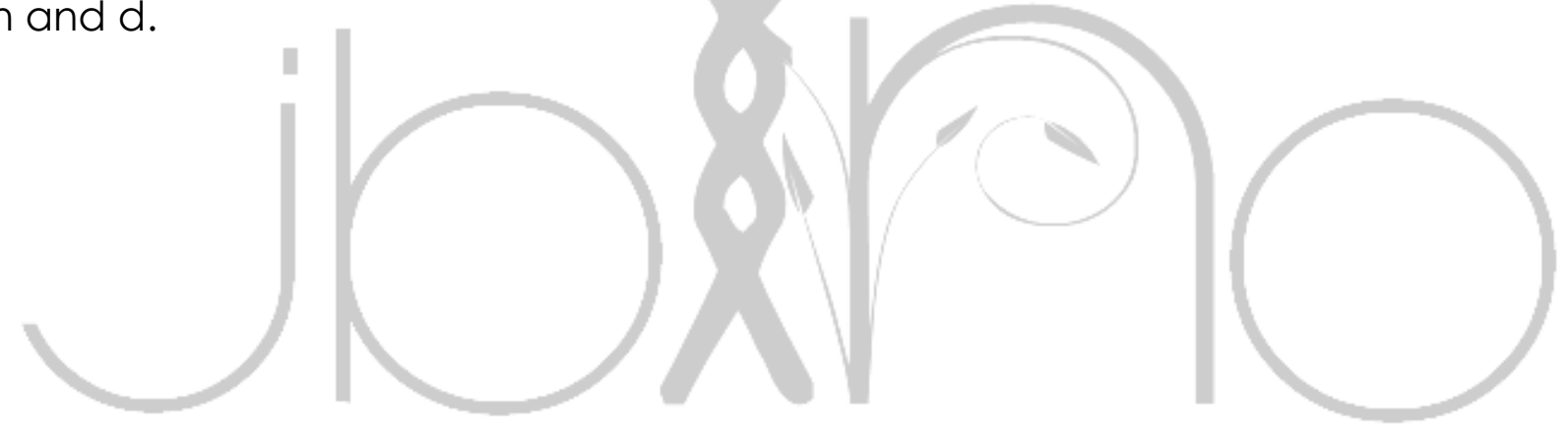




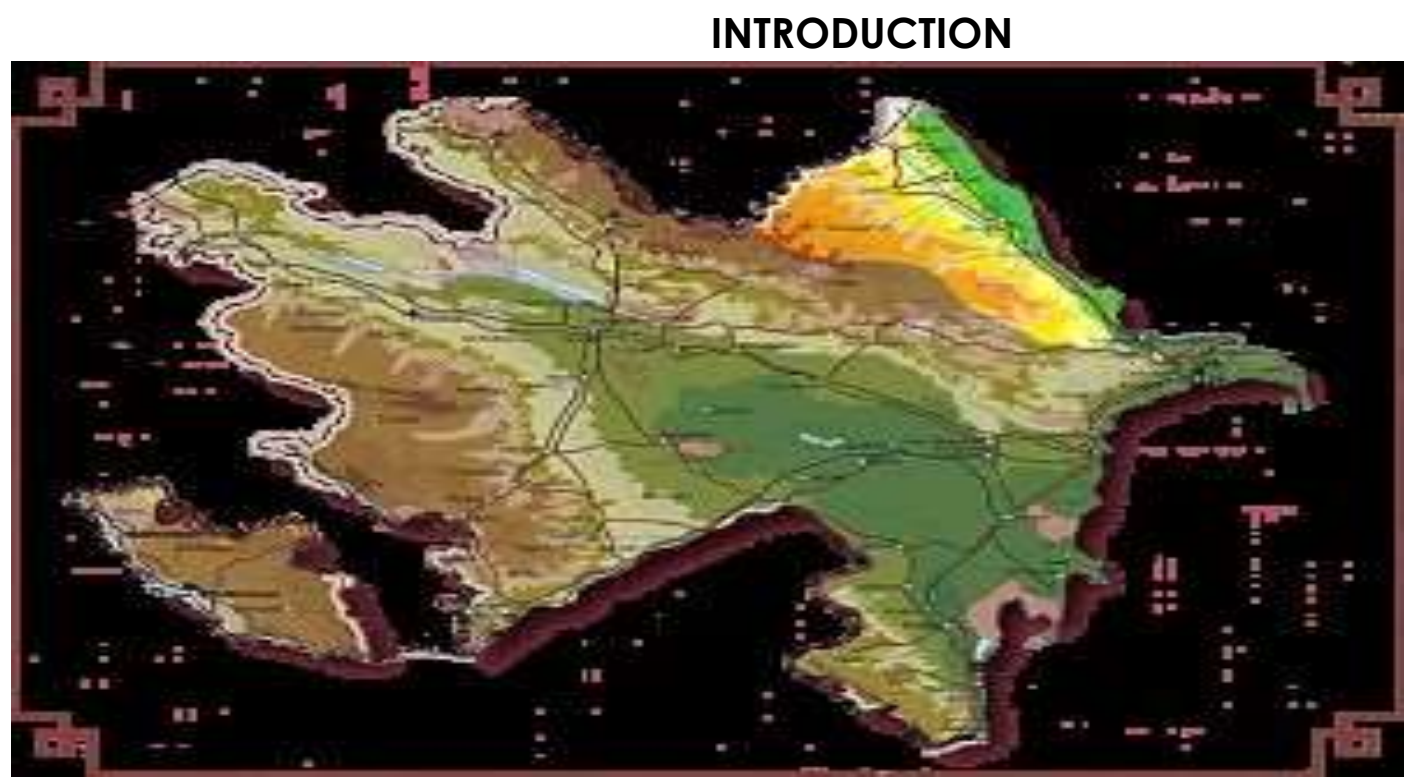

Aqsu region, situating in south-east slope of Great Caucasian has 393, 3 thousand hectare area. The area of region is situated in 200-2500 $\mathrm{m}$. height above seal level.As in all regions of Great Caucasian, this region is belonged to low mountainous zone, from geological and geomorphologic point of view. In soil formation process, rocks play a great role in formation of their fertility. When the rocks, rich with mineral elements are weathered in the region, absorbs into soil a great number of nourishment elements.

A lot of potassium and other elements are absorbed into the structure of soils, of which hydro mica arises from field's par, mica and slates. In mountainous part of the region, soil former rocks mainly consist of slates, marls and sandy.

But in watersheds, basalt, marble and granites are met.

In middle mountainous part the rocks mainly consist of clayey slates, clay with lime mixture and sandy.

As it is known, climate plays a very great role in soil formation process. V.V. Dokuchayev[1], I.P.Gerasimov [2],
I.F.Figurovski [3], A.Shikhlinski [4], and others have informed about a great role of climate in erosion formation process.

Climate of Shamakhi region corresponds to the climate of Middle Europe. Here, the minimum temperature is observed between $3^{\text {rd }}$ ten days of December and $2^{\text {nd }}$ ten days of February. And the maximum temperature is observed in February, July-August months.

Average yearly quantity of rains is about $460-600 \mathrm{~mm}$.

Mountain and meadow, mountain and forest, mountain-chernozem, mountain and grey-dark brown soils have spread in region area.

Because of our investigation covers mountain-chernozem, we dwell on their main character.

V.V.Akimitsev [9], M.A.Salayev [10], G.B.Salamov [11], B.G.Shakuri (8) and others have noted on spreading of chernozem in mountain zone of Azerbaijan. Chernozems have spread in limited area in Great Caucasian and are strongly used under agriculture plants. 
They have mainly developed in middle mountainous area of Shamakhi and Ismayilli regions.

The course of research and discussion of materials:

We have investigated mountainchernozems in Shamakhi region. Morphological description of soils types, flushed in average degree and subjected to erosion is indicated below.

\section{Section 1:}

Divided in the region of Jabani village, gentle east Bakharli slope.

A 0-17 cm chernozem clayey, heap, hard, dry, plant roots, rootlets, worm ways, small stones, boils for the impact of chlorine acid, the passage is clear.

B 17-39 cm-chernozem, upper layer is relatively light, clayey, heap a little hard,

root and rootlets, small stones, spots in brown vein form, worm ways, damp, boils for the impact of chlorine acid, passage is gradual. 
J.Bio.Innov 9(3), pp: 345-351, 2020 |ISSN 2277-8330 (Electronic)

Table 1

Stutuctural aggregate composition of carbonated mountain-black soil

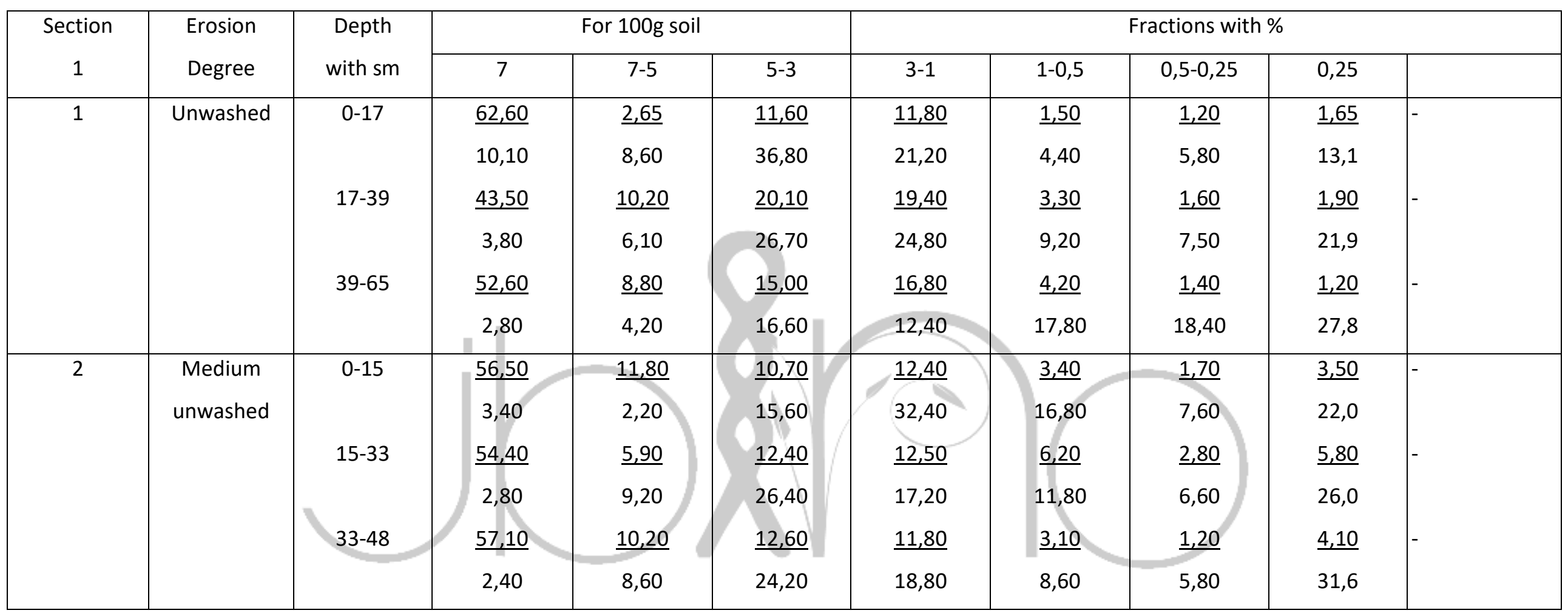

\begin{tabular}{|c|c|c|c|c|c|c|c|c|c|c|}
\hline \multirow[t]{2}{*}{ Section 1- } & \multirow{2}{*}{$\begin{array}{c}\text { Erosion } \\
\text { degree }\end{array}$} & \multirow{2}{*}{$\begin{array}{l}\text { Depth } \\
\text { with sm }\end{array}$} & \multirow{2}{*}{$\begin{array}{l}\text { Hygroscopic } \\
\text { humidity }\end{array}$} & \multicolumn{7}{|c|}{ Fractions' measure with $\mathrm{mm}$, quantity with $\%$} \\
\hline & & & & $1-0,25$ & $0,25-0,05$ & $0,05-0,01$ & $0,01-0,005$ & $0,005-0,001$ & $<0,001$ & $<0,001$ \\
\hline \multirow[t]{2}{*}{1} & \multirow[t]{2}{*}{ Unwashed } & $0-17$ & 5,74 & 4,63 & 6,17 & 29,20 & 15,20 & 15,20 & 15,20 & 60,00 \\
\hline & & $17-39$ & 6,41 & 0,32 & 10,88 & 24,40 & 19,60 & 19,60 & 18,40 & 64,40 \\
\hline
\end{tabular}

2020 May Edition | www.jbino.com | Innovative Association 
J.Bio.Innov 9(3), pp: 345-351, 2020 |ISSN 2277-8330 (Electronic)

Aliyev et al.,

\begin{tabular}{|c|c|c|c|c|c|c|c|c|c|c|}
\hline & & $39-65$ & 6,71 & 2,40 & 9,20 & 19,20 & 18,40 & 18,40 & 18,40 & 69,28 \\
\hline \multirow[t]{3}{*}{2} & \multirow{3}{*}{$\begin{array}{l}\text { Medium } \\
\text { washed }\end{array}$} & $0-15$ & 5,28 & 0,30 & 9,82 & 32,40 & 14,84 & 14,84 & 22,40 & 57,48 \\
\hline & & $15-33$ & 5,65 & 0,40 & 12,76 & 24,08 & 12,96 & 12,96 & 25,60 & 62,76 \\
\hline & & $33-48$ & 6,24 & 4,58 & 6,62 & 22,40 & 16,80 & 16,80 & 14,40 & 66,40 \\
\hline
\end{tabular}

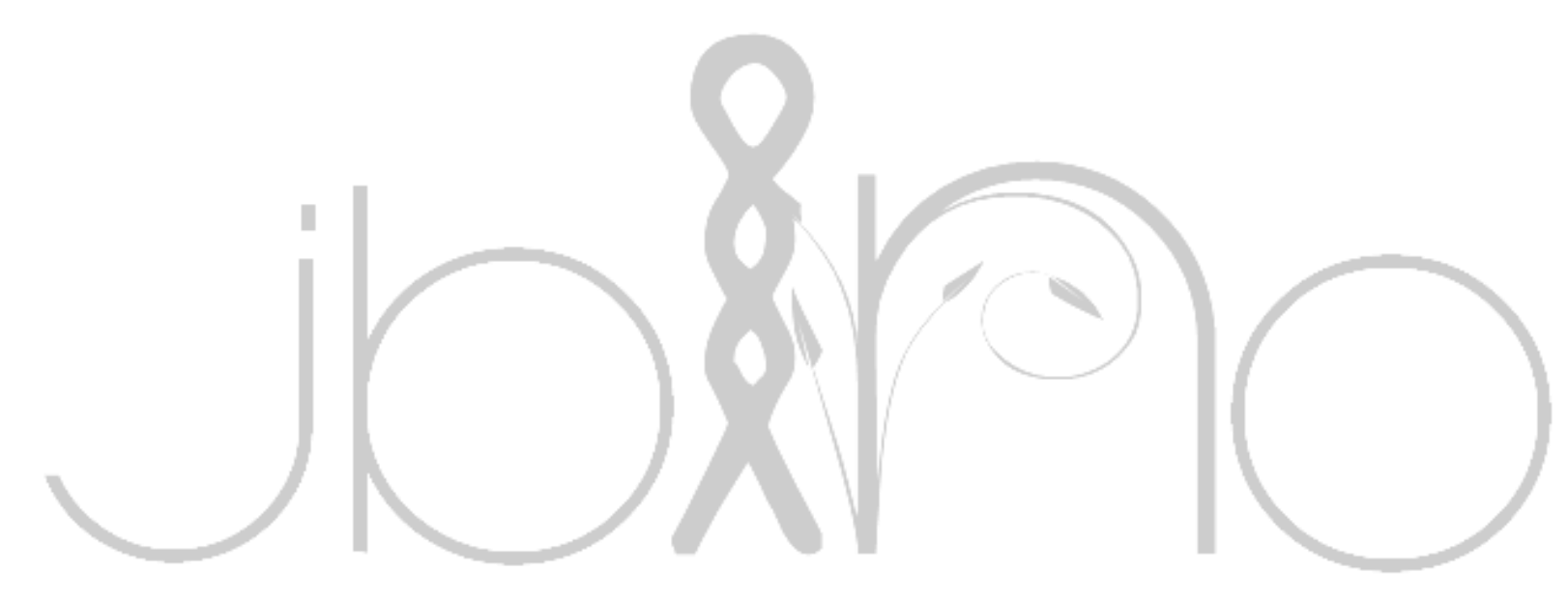

2020 May Edition | www.jbino.com | Innovative Association

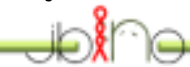


B/C-39-65 cm - color is more lighter, clayey, heap, solid, root, rootlets as weak vessel carbonate spots, stone, rocks boils from $\mathrm{HCL}$ effect.

Morphological description shows that the soil, we have investigated, are the carbonated half type of mountain black soil.

The area where these types of soil are situated has the compound physical condition. In the result of complexity of physical condition and mutual effect of anthropogenic factors erosion process has developed.

Taking into consideration the damages, which erosion process inflicted to soil fertility, there was put sections in this type of soil. Morphological description of such sections is given below.

\section{Section 2.}

$B_{1}$ 0-15 cm- light black, heavy clayey, heap, little stones, root and rootlets boiled weakly, boils from $\mathrm{HCL}$ effect, passage is clear.

\section{$B_{2} \mathbf{1 5 - 3 3} \mathrm{cm}$ - light black, clayey,} heap, very solid, small and flat stones, sparse root and rootlets, limestone boils from $\mathrm{HCL}$ effect, passage is clear.

B/C 33-48 cm - light black, clayey, heap, very solid, flat white stones, weak carbonate vessels sparse root and rootlets boils from HCL effect.

Cover in these regions is sparse. As indicated in morphological description of section "A" layer structure was disordered and other physical factors have subject to deformation. Some chemical factors of mountain - black soil were indicated in schedule No 1 and No 3.

As indicated in schedule No 1 amount of waterproof aggregates in middle flushed soil than in non-flushed soil was decreased, and this shows the disorder of such soil structure. Amount of physical clay in the type of flushed mountainblack soil has decreased and mechanical composition has become lighter. (Schedule No 1 and 2).

Amount of humus in non-flushed type of mountain-black soil was 5.35-1.94\%, common nitrogen is $0.26-0.10 \%$.

The soil is carbonated, carbonates $\left(\mathrm{CaCO}_{3}\right)$ was $3.57-2.73 \%$.

This soil is saturated with alkali.

So, total of absorbed ground was 28.2$29.2 \mathrm{~m}$. ekv (IOOgr soil) along profile. Calsium has priority in cations.

Mounting chernozem soils are well provided by nutrients.

As evident from figures of schedule No.3 quantity of phosphorus (PiOs) solved in profile alkali was $33.3-27.2 \mathrm{mg}$ ( $1 \mathrm{~kg}$. soil), exchanged potassium $(\mathrm{K} \wedge \mathrm{O})$ was $442.0-$ $335.0 \mathrm{mg} / \mathrm{kg}$.

As can be seen from figures of the table mounting chernozem soils have a good potential of prolificacy. As erosive process changed morphological characters of the soils, it has influence on its prolificacy parameters.

Results of my investigations also show it. It is possible to see it from the numerals of schedule No.2.

As we see, the amount of humus was 3 , 48-1,36\% general nitrogen in the profile of carbonate mountain chernozem subject to erosion in middle degree, and as a result it has decreased in compare of unwashed soils.

In the profile of those soils was $\mathrm{CaCO}_{3} 2$, 18-1, $77 \%$, and sum of absorbed bases was 31, 5025,5 m. ekv. (in 100 gr. soil). Here the amount of phosphor dissolved in alkali is between $27,3-23,9 \mathrm{mg} / \mathrm{kg}$ and changeable potassium is between 305,0 246,0 . 
We can come into the following conclusions from the investigation we held:

\section{Conclusion}

1. Mountain chernozems include to the soil groups situating in the vertical direction of south-east slope of Great Caucasus.

2. Mountain chernozems have high fertile potential.

3. Erosion process decreases more the fertile potential of mountain chernozems.

\section{Literature}

[1]. Dokuchaev V.V. Prior account on investigations in the Caucasus in summer of 1899. Press. The Caucasus, IRTO Department, v. XII, pub.3, 1899

[2]. Gerasimov I.P. Scientific basis of systematization of soils. Tr. soilsof institute named after V.V. Dokuchaev. $v$. XXVIL, 1948.

[3]. Figure vsky I.V. Climate of the Caucasus (prior account). Tiflis, 1919

[4]. Climate of Azerbaijan (1,2,8, ॥ section). Press. AS of Azerbaijan SSR, BakU, 1968, p.743
[5]. Shikhlinski A.M. Defense of soil from erosion. Baku, Azernashr., 1967,p.25-36.

[6]. Mustafaev Kh.M. Alakbarov K.A. Increasing of erosion in the south slope of the Great Caucasus and basis of struggle with them, Baku, 1975.

[7]. Shakuri E.G. Investigation of fertility of soils subject to erosion of the Republic of Azerbaijan in recent 50 years. Report Journals devoted to 50 years annual of SR "Erosion and Irrigation" Institute., Baku, 2001, p. 17-22.

[8]. Shakuri E.G. Fertility of basic types of mountain-soil zones of Great Caucasus south-east extremity and factors influencing to its parameters. Monography, Baku, 2001, p.115.

[9]. Akimtsev V.V. Ganja region soils. Materials on zoning of Azerbaijan SSR., v. 2, Press 5, Baku, 1927

[10]. Salayev M.E. Soil formation conditions and top-soil in Azerbaijan in $\mathrm{km}$.

[11]. Salamov Q.B. Formation and characteristics of chernozem soil of foreststeppe and forest zone of the Great Caucasus. Baku, 1961. 